\title{
Acceptance and Re-verification Test of Length Metroscope
}

\author{
Tatiana Kelemenová, Michal Kelemen*, Miková Lubica, Ivan Virgala, Vladislav Maxim, Tomáš Lipták, \\ Milan Lorinc \\ Faculty of Mechanical Engineering, Technical University of Kosice, Kosice, Slovakia \\ *Corresponding author: michal.kelemen@tuke.sk
}

Received October 07, 2014; Revised October 15, 2014; Accepted November 10, 2014

\begin{abstract}
Paper deals with acceptance and re-verification of length measuring metroscope. The metroscope has been used very frequently for exercises in subject - Engineering Metrology at the bachelor study. New systematic errors have been obtained from calibration process. Other measurements have been also realized and corrections of results have been executed via using of new systematic errors. Measured errors from acceptance test have confirmed that metroscope is out of the limits defined through the maximum permissible error. Nevertheless the metroscope is fully functional and errors could be eliminated through the including of new measuring system consisting from suitable distance sensor.
\end{abstract}

Keywords: metrology, measurement, systematic error, gauge blocks

Cite This Article: Tatiana Kelemenová, Michal Kelemen, Miková Lubica, Ivan Virgala, Vladislav Maxim, Tomáš Lipták, and Milan Lorinc, “Acceptance and Re-verification Test of Length Metroscope.” American Journal of Mechanical Engineering, vol. 2, no. 7 (2014): 274-277. doi: 10.12691/ajme-2-7-21.

\section{Introduction}

The quality of measurement is determined by its accuracy, which often determines the measurement cost. Knowledge of measurement accuracy is required to compare the results of measurement of the same physical quantity obtained by different operators, to define safe ranges for parameters of technological processes, and to estimate reliability of product quality control, as well as in almost all other applications of measurements. Measurement errors and uncertainties are the most important problems that physicists and engineers encounter when estimating errors and uncertainty.

The goal of measurement is to obtain the true value of the measurand. The error of the measurement result describes the proximity of the result to the true value. Error is a model concept and cannot be used to calculate error directly. Error estimation presupposes evaluation of the individual characteristics of the error.

An error is defined as the measured difference between the measuring instrument indication and the known value of the measurand it is measuring. The numerical value of an error changed in sign can be applied as correction. Any result of measurement, as well as error and corrections, has an associated quantifiable uncertainty.

The discrepancy between an accepted value of a parameter and an experimentally measured value results from deviations in the manner in which the measurement is carried out. No two measurements are exactly the same. Some deviations can be controlled and some cannot. Those that can, in principle, be controlled by careful adjustment of the experimental procedure are systematic errors. They definite values that can, in principle, be measured and corrected. Systematic errors are sometimes called determinate errors. The most common error types are instrumental error, operator error, and method error.

Calibration is an experimental procedure which permits the determination of errors with respect to system indications. These system indications, when corrected, are required to be traceable to recognized reference standards. Traceability is therefore an attribute of results of measurement and it is achieved within a stated uncertainty. Of course, any calibration result is valid only under specified conditions [1-5].

It is important not to confuse the terms 'error' and 'uncertainty'. Error is the difference between the measured value and the 'true value' of the thing being measured. Uncertainty is a quantification of the doubt about the measurement result. Whenever possible we try to correct for any known errors: for example, by applying corrections from calibration certificates. But any error whose value we do not know is a source of uncertainty [612].

A gauge block is a length standard having flat and parallel opposing surfaces. Gauge blocks have nominal lengths defined in either the metric system (millimeters) or in the English system (1 inch = $25.4 \mathrm{~mm})$. The length of the gauge block is defined at standard reference conditions (temperature $=20^{\circ} \mathrm{C}\left(68^{\circ} \mathrm{F}\right)$; barometric pressure $=$ 101,325 Pa (1 atmosphere); water vapor pressure $=1,333$ $\mathrm{Pa}$ (10 mm of mercury); $\mathrm{CO}_{2}$ content of air $=0.03 \%$ ).

Of these conditions only the temperature has a measurable effect on the physical length of the block. The other conditions are needed because the primary 
measurement of gauge block length is a comparison with the wavelength of light. For standard light sources the frequency of the light is constant, but the wavelength is dependent on the temperature, pressure, humidity, and $\mathrm{CO}_{2}$ content of the air.

Gauge blocks are calibrated by interferometry in accordance with the definition of gauge block length. The mechanical length of a gauge block is the length determined by mechanical comparison of a block to another block of known interferometrically determined length. The mechanical comparison must be a measurement using two designated points, one on each end of the block. Since most gauge block comparators use mechanical contact for the comparison, if the blocks are not of the same material corrections must be made for the deformation of the blocks due to the force of the comparator contact [13].

\section{Description of Metroscope}

Length metroscope (Figure 1) is measurement equipment for measurement of outer and inner dimensions of parts via using contact method. Result of measurement is direct reading value of measured dimension. The principles formulated by prof. Ernst Abbe in 1890 have strictly been considered to ensure the required high accuracy of the length metroscope.

These principles are as following:

1) Any measurement, no matter whether by contact setting or by setting the line of sight, must always be based on a length graduation with which the length to be measured is directly compared.

2) The measuring apparatus must be arranged so that the length to be measured is the straightlined continuation of graduation used as a scale.

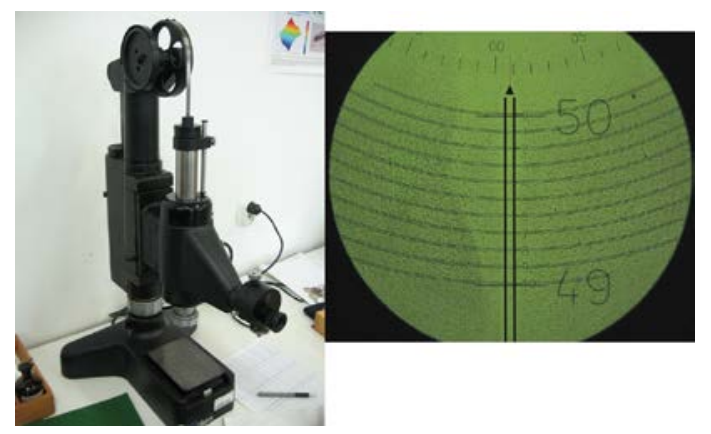

Figure 1. Length measuring device and view of indicated measured value in the microscope

Measuring operations with metroscope are generally performed directly by comparing the test object with a precision glass scale whose graduation lines are observed in microscope. The glass scale is connected to a measuring sleeve and arranged in its vertical axis. These displacements are indicated in the microscope and read by the operator as measured value.

The measuring element contains the measuring sleeve, spiral microscope as indicating device (Figure 1) and lighting equipment. The measuring sleeve contains the glass scale with milimeter graduation along $100 \mathrm{~mm}$. Constant measuring force is ensured via using of precision weights. Measurement range is $100 \mathrm{~mm}$ and resolution is $1 \mu \mathrm{m}$.

\section{Previous Systematic Error and Maximum Permissible Error}

Producer declares table with systematic error for every milimeter of graduated scale. Graphical representation of these systematic errors is shown on Figure 2. As it is visible these errors are in a range between $0.1 \mu \mathrm{m}$ to -0.6 $\mu \mathrm{m}$. Every measured value has to be corrected with corresponding systematic error known from this table.

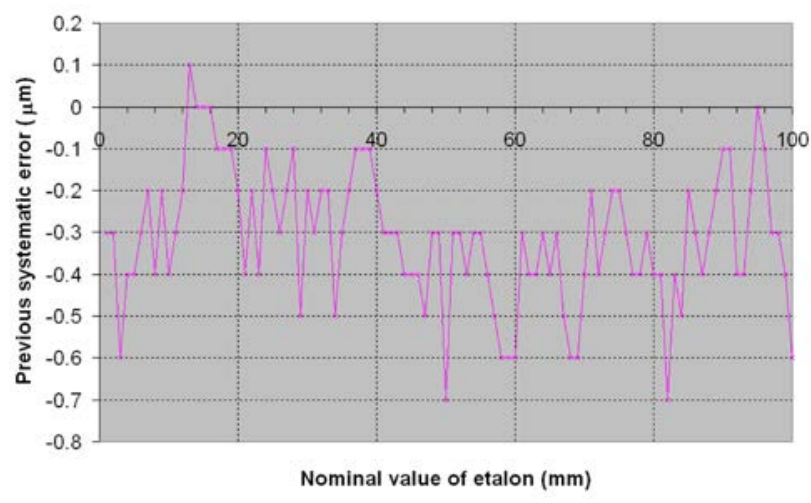

Figure 2. Previous systematic error declared by producer

Producer also defines maximum permissible error of indication - MPE:

$$
M P E= \pm\left(1.5+\frac{L}{400}\right)
$$

where

- MPE is Maximum Permitted Error $(\mu \mathrm{m})$;

- $L$ is measured milimeter scale division (mm).

The equation is unit incompatible because it is empiric relation obtained from experimental calibration realised by producer. Metroscope is device made in year 1962 and it is frequently used in didactic process every year more than 40 years. Students learn basic routine of working with length metroscope and they obtain experiences from length metrology. Approximately 200 students practice with the metroscope every year. It means many people and sometimes rough manipulation. Ravages of times also cause deterioration of the metroscope. New calibration or more precisely re-verification (Figure 3, Figure 4) is necessary for obtaining of new systematic error and acceptance test of the metroscope.

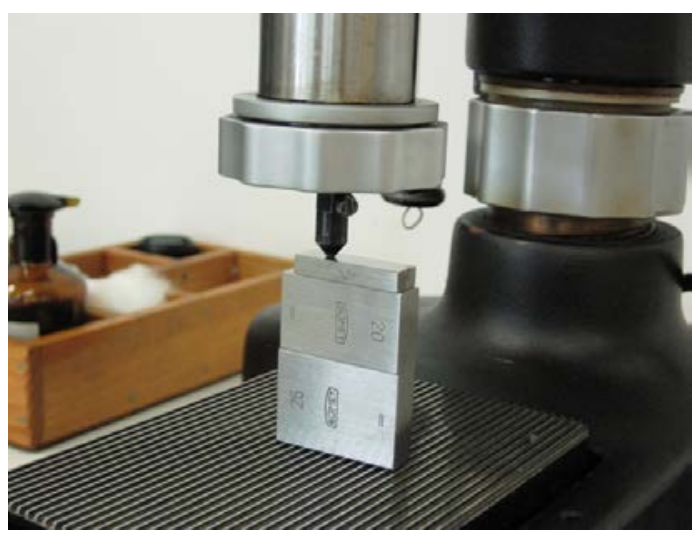

Figure 3. Calibration of length measuring device using the length gauge blocks 


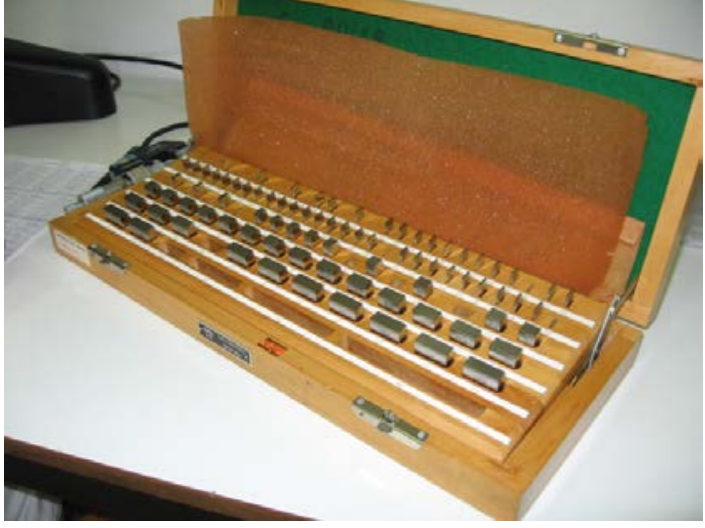

Figure 4. Set of length gauge blocks

\section{Re-verification Tests of Metroscope}

Set of parallel length gauge blocks (Figure 4) have been used for this purpose. Every milimeter of scale division has been checked with length gauges. Results are new systematic errors shown in Figure 5 (graphically shown with old previous systematic error defined by producer). Every point is obtained as arithmetic mean of 10 measurements realised at the same conditions. It is visible that new systematic errors confirm degradation process of the metroscope. All errors are rapidly shifted and also they are more dispersed.

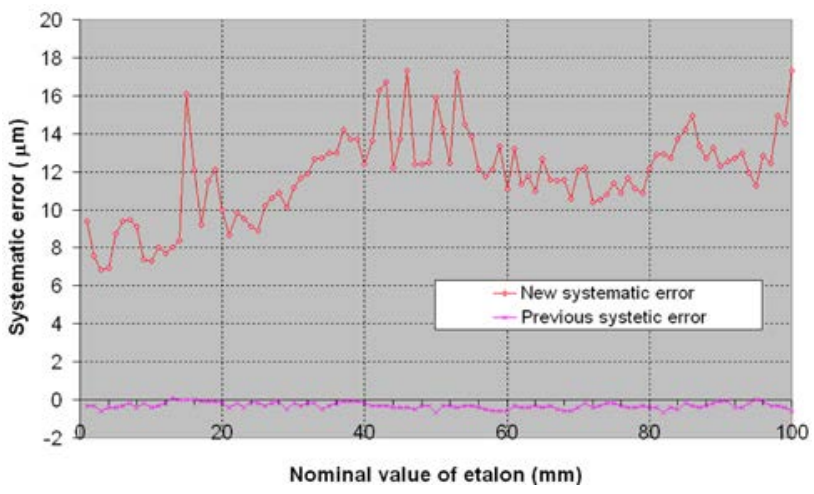

Figure 5. Previous and new systematic error of metroscope

New systematic errors are approximated with polynomial function (Figure 6) because of better using in computer processing.

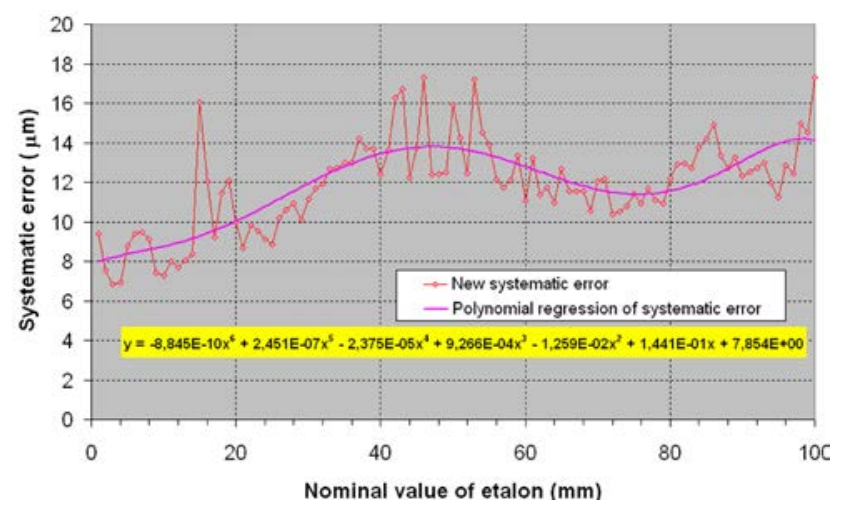

Figure 6. New systematic error of metroscope with polynomial approximation

\section{Acceptance and Tests of Metroscope}

The principle of the acceptance method is used to establish whether the metroscope is capable of measuring within the manufacturer's stated values of maximum permission error $(M P E)$. If none of the error of length values is greater than $M P E$ then the performance of the metroscope is verified.

Acceptance test and re-verification have been done in two steps:

- Test with measurement of every 5th milimeter of graduated scale of metroscope (Figure 7).

- Test with measurement of 10 randomly selected values of graduated scale of metroscope (Figure 8).

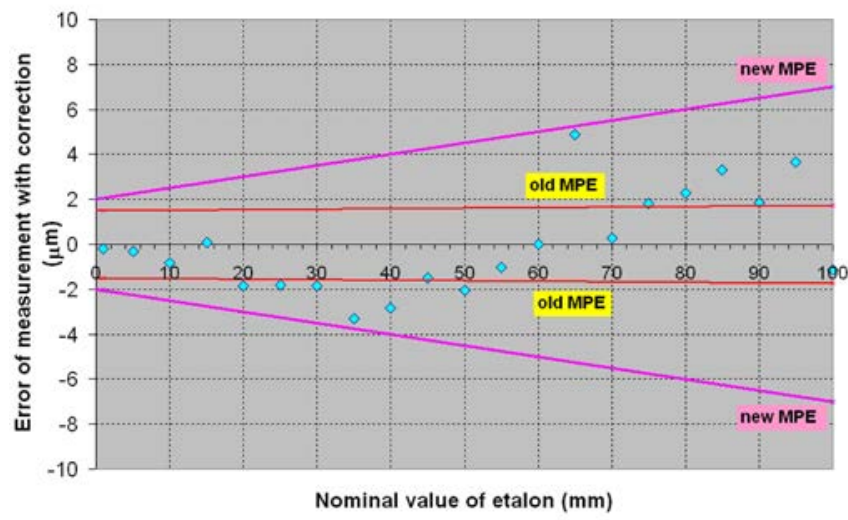

Figure 7. Measurement of every 5th milimeter of graduated scale for acceptance and tests of metroscope

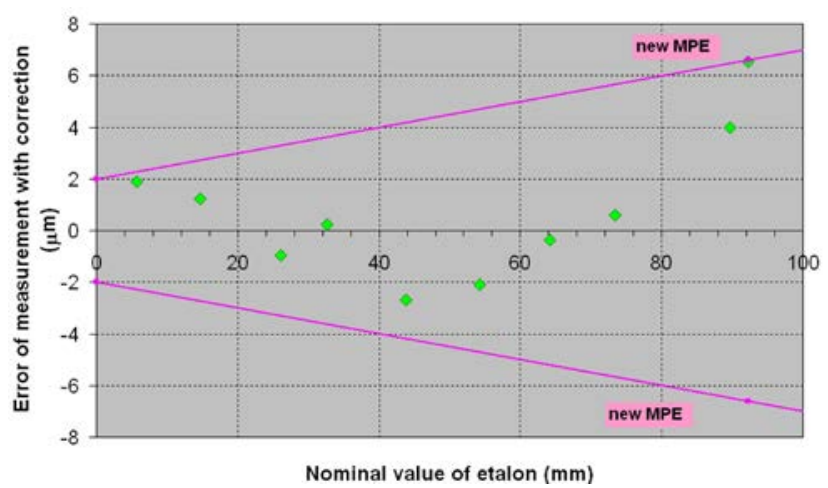

Figure 8. Measurement of 10 randomly selected values of graduated scale for acceptance and tests of metroscope

Both tests have been realized with set of length gauge blocks. Every measurement was repeated 10 times at the same conditions. As it is visible, metroscope did not pass over verification test.

If we want to use it for measurement, the new maximum permission error (MPE) has to be established. New MPE is described as:

$$
M P E= \pm\left(2+\frac{L}{20}\right)
$$

where MPE is Maximum Permitted Error $(\mu \mathrm{m}) ; L$ is measured milimeter scale division ( $\mathrm{mm}$ ).

Measurement of 10 randomly selected values of graduated scale shows that metroscope has been passed over the acceptance test with new values of maximum permission error (MPE). 


\section{Conclusion}

Metroscope is made in year 1962. More than 40 years our students learnt on this machine. The machine has gone through the hands of eight thousands students. Nevertheless to these facts, the machine is still functional. Acceptation test shows that MPE become worse, but new systematic errors and MPE has been established. Metroscope is still useful for general use in dimensional metrology. Next step is including of suitable distance sensor for electronic reading of measured values. There are expectations of improved maximum permission error of metroscope after installation of this sensor [14-24].

\section{Acknowledgement}

The authors would like to thank to Slovak Grant Agency - project KEGA 005STU-4/2012 and VEGA $1 / 0085 / 12$. Paper is the result of the Project implementation: University Science Park TECHNICOM for Innovation Applications Supported by Knowledge Technology, ITMS: 26220220182, supported by the Research \& Development Operational Programme funded by the ERDF.

\section{References}

[1] Rabinovich, S. G., Measurement Errors and Uncertainties. Theory and Practice. Springer New York. 3rd ed. 2005, XII, 308 p.

[2] Rabinovich, S. G.. "Accuracy of single measurements". Accreditation and Quality Assurance, August 2007, Volume 12, Issue 8, pp 419-424.

[3] Schwenkea, H., Knappb, W., Haitjemac, H., Weckenmannd, A., Schmitte, R., Delbressine, F., "Geometric error measurement and compensation of machines-An update", CIRP AnnalsManufacturing Technology. Volume 57, Issue 2, 2008, Pages 660675.

[4] Chunovkina, A.G., "Terminology. Measurement Error, Measurement Uncertainty, Measurand Uncertainty”. Measurement techniques, Vol. 43, No. 7, 2000, pp. 581-586.

[5] Sartori, S., Zhang, G.X., "Geometric Error Measurement and Compensation of Machines”, CIRP Annals-Manufacturing Technology, Volume 44, Issue 2, 1995, Pages 599-609.

[6] John R. Taylor, An Introduction to Error Analysis: The Study of Uncertainties in Physical Measurements, 2d Edition, University Science Books, 1997.

[7] Philip R. Bevington and D. Keith Robinson, Data Reduction and Error Analysis for the Physical Sciences, 2d Edition, WCB/ McGraw-Hill, 1992.

[8] Bell, S., “A Beginner's Guide to Uncertainty of Measurement”, The National Physical Laboratory is operated on behalf of the DTI by NPL Management Limited, a wholly owned subsidiary of Serco Group plc. Measurement Good Practice Guide No. 11 (Issue 2), August 1999.

[9] Chudy, V., Palencar, R., Kurekova, E., Halaj, M., Measurement of technical quantities. STU Publishing, 1st. edition, 1999.

[10] Kreith, F., The Mechanical Engineering Handbook Series. CRC PRESS. New York.

[11] JCGM 200-International vocabulary of metrology-Basic and general concepts and associated terms (VIM) 3rd edition (2008 version with minor corrections). (C) JCGM 2012 Available online: http://www.iso.org/sites/JCGM/VIM-JCGM200.htm

[12] JCGM 104-Evaluation of measurement data-An introduction to the "Guide to the expression of uncertainty in measurement" (ISO/IEC Guide 98-1). First edition July 2009. Available online: http://www.bipm.org/en/publications/guides/gum_print.html

[13] Doiron, T., Beers, J., The Gauge Block Handbook, Dimensional Metrology Group, Precision Engineering Division, National Institute of Standards and Technology, 1995, Monograph (NIST $\mathrm{MN}), 145$ pages.

[14] Duchoň, F., Hanzel, J., Babinec, A., Rodina, J., Pásztó, P., Gajdošík, D., "Improved GNSS Localization with the Use of DOP Parameter”, In: Applied Mechanics and Materials.-ISSN 16609336.-Vol. 611 (2014), pp. 450-466.

[15] Pyszko, R., Koval, L., Machackova, A., Kleckova, Z., Jedlicka, Z. "Embedded control system of apparatus for measurement of thermal conductivity”, Proceedings of the 7th WSEAS International Conference on Automatic Control, Modeling and Simulation, (2005), pp. 113-117.

[16] Wilhelm, R.G., Hocken, R., Schwenke, H., „Task Specific Uncertainty in Coordinate Measurement”, CIRP AnnalsManufacturing Technology, Volume 50, Issue 2, 2001, Pages 553563.

[17] Dovica, M., Zivcak, J., Kelemenová, T., Measurement of geometric quantities in mechanical engineering, Technical University of Kosice Publishing, $1^{\text {st }}$ edition, 2011, 290 pages.

[18] Koniar, D. Hargaš, L. Hrianka, M., "Measurement of Object Beating Frequency Using Image Analysis", Applied Electronics 2009, Internal Conference, Pilsen, 9-10 September 2009, IEEE Catalog Number CFP0969A-PRT.

[19] Dekan, M., Duchoň, F., Jurišica, L., Vitko, A., "Probabilistic Model of Laser Rangefinder". In: $A D$ ALTA: Journal of Interdisciplinary Research. -Vol. 1, Iss. 2 (2011), pp. 151-155.

[20] Dovica, M., Kelemenová, T., Henriczyová, T., Coordinate metrology, $1^{\text {st }}$ edition, publisher: Technical University od Kosice, 2012, 483 pages.

[21] Busch, K., Kunzmann, H., Wäldele, F.: “Calibration of coordinate measuring machines”, Precision Engineering, Volume 7, Issue 3, July 1985, Pages 139-144.

[22] Koniar, D., Hargaš, L., Hrianka, M., Špánik, P., “Application of DICOM Standard in LabVIEW Environment”, In: Sensors \& Transducers Journal, Vol. 87, Issue 1, January 2008, pp. 19-23.

[23] Vitko, A., Jurišica, L., Babinec, A., Duchoň, F., Kl'účik, M., "Resolution of Robot Kinematic Redundancy as a Problem of Adaptive Control”, In: AT\&P Journal Plus.-ISSN 1336-5010.-No. 1: Systems of Automatic Control (2010), pp. 58-61.

[24] Acko, B., "Calibration of measuring instruments on a coordinate measuring machine”, Advances in Production Engineering \& Management 2 (2007) 3, pp. 127-134. 